\title{
A new reciprocal linkage for expandable emergency structures
}

\section{J. Pérez-Valcárcel(*), F. Suárez-Riestra, M. Muñoz-Vidal, I. López-César, M. J. Freire-Tellado}

\author{
Grupo de Estructuras Arquitectónicas (GEA). Estructuras singulares (GES) \\ Escuela Técnica Superior de Arquitectura. \\ Universidade da Coruña. Campus da Zapateira s/n. 15071 A Coruña. Spain
}

$\left(^{*}\right)$ e-mail: valcarce@udc.es

\begin{abstract}
Expandable structures have certain qualities in terms of lightness and transportability which make them very useful as emergency buildings, a research line that is being developed by the authors. However, these structures have some disadvantages due to their reduced rigidity and great deformability, issues that could limit their use. This paper analyzes a reciprocal linkage that considerably improves one of the main problems of expandable structures, which is their lack of rigidity. The extremely strict geometrical conditions for this proposed linkage and the mechanical behaviour are examined. Two series of tests were carried out, with specimens formed by four bars supported reciprocally around the proposed linkage. In the first case, the bars had their ends simply resting on the base and in the second one displacement was restricted at their ends. Theoretical analysis and the experimental tests results are also included. The tests make it possible to define the failure patterns of the different elements of the linkages, bars or bolts. The theoretical models and the experimental results show that the proposed reciprocal linkages are highly effective. Tests of plane scissor meshes were also carried out using reciprocal linkages, showing a very significant reduction in their displacements.
\end{abstract}

Keywords: Expandable structures; reciprocal linkages; lightweight structures; temporary buildings; emergency buildings.

\section{Introduction}

Emergency buildings require special features which allow them to overcome any problems that could arise. They firstly have to be transportable, given that any existing buildings have probably been destroyed or damaged. They must be as light and compact as possible so that transport is easy and economical, while also creating enclosed spaces that can be used by the local population. Expandable structures are a suitable response to the above requirements. They can be folded down into a highly compact package of bars, and as they are light and small when folded they are easy to transport. Once they are in place they can be expanded to cover a large area (figure 1).

The first studies of expandable spatial structures were carried out by Emilio Pérez Piñero [1,2]. His proposals were based on modules of trusses composed of three or four bars joined at a central point. Although the early death of this architect prevented these proposals from being immediately developed, new research began to appear after the 1980s. This included studies and proposals by Escrig, Valcárcel and Sánchez [3,4,5], Hernández [6], Gantes [7], Hoberman [8], Sánchez Cuenca [9] and others. The subject has been revitalised by several interesting recent studies [10,11,12]. These studies usually are focused on modules of $\mathrm{x}$-cross bars composed of three or four scissors that are joined at their ends.

In spite of this relative abundance of studies, few buildings have actually been constructed. The two largest executions are the exhibition pavilion for the " 25 years of peace" exposition, by Pérez Piñero in 1964 [13] and the roof of San Pablo swimming pool in Seville [14,15]. This previous researches has usually centred on roofs for relatively wide spans. The roof modules by Pérez Piñero were designed for spans of about 30 metres, and the San Pablo swimming pool roof by Escrig, Sánchez and Valcárcel covered an area of 30 by 60 metres. This fact demands relatively complex solutions in terms of linkages as well as bars. However, the buildings studied by our team are from 12 to 18 metres of 
span. This makes it possible to use simpler linkages and bars without additional elements, such as the fins used in the Seville swimming pool (figure 2).

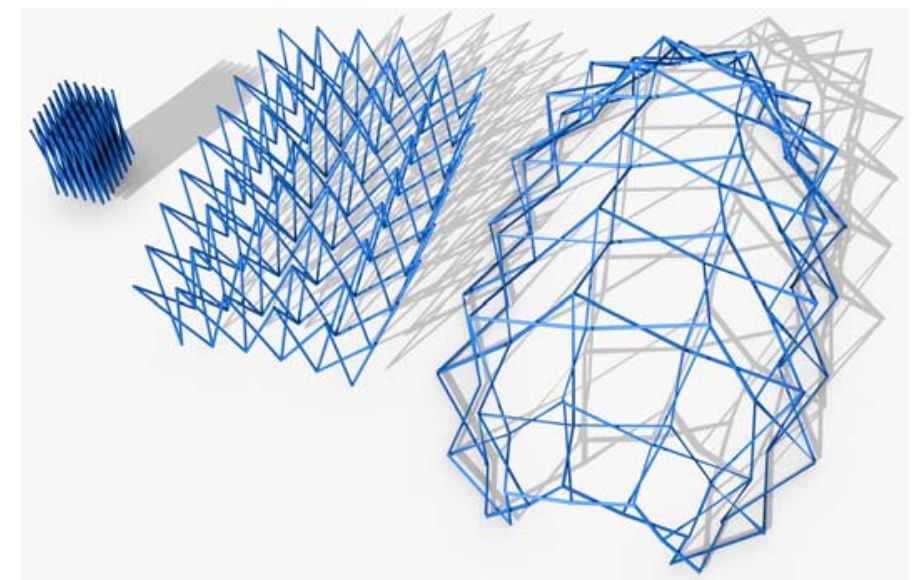

Figure 1.- Prototype of the deployable structure developed by our team.

Linkage design is one of the essential aspects of deployable structures. Such linkages must permit the turns necessary during deployment and folding, guaranteeing the transmission of forces with the least possible eccentricity. They also have to ensure that movements of the bars are geometrically compatible with all intermediate states, so that they do not collide. The conditions described above mean that the linkages and bars are highly interdependent, so that when studying the linkages, the number and type of bars involved must be taken into consideration, together with their angle and the degrees of freedom they have to restrict. The bars should be light, given that expandable structures are made to be transported. They should also be cheap, as they account for a significant proportion of the total cost.

The researchers therefore paid special attention to the design of the bars. The pioneering work of Pérez Piñero centred on the linkages. These were subsequently patented, and they are still the simplest and most effective linkages for modules of bars.

The scissor modules formed by SLE (Scissor Like Elements) require linkages of another type. These were subjected to numerous studies, which although they produced many solutions did not achieve an optimum design. The most complex solutions are systems similar to universal joints, with turning axles and concurrent bars, such as the patent by Emmerich [16] or the double articulated linkages mentioned by De Temmerman [10]. Their drawback is that they are large and complicated to manufacture. Although they are effective, they are also complex, heavy and expensive.

Another set of proposals are based on linkages with concurrent bar axles which turn eccentrically, and these usually require special arrangements of bars. Pérez Piñero resolved this question by using crooked guide bars [1]; Gantes proposed a solution involving simple articulated bars over a disc [17]; Akgün et al. [18] use scissors in which one bar is double and the other is simple, closing within the double bar. Roovers and De Temmerman developed a linkage based on the one by Gantes to permit complementary movements of the bars, such as in strutted elements [19]. Gómez Jaúregui patented another type of linkage based on the same principle, but using U-shaped parts instead of a disc [20].

Linkages formed of metal crossheads composed of fins with eccentric axles and bars. Although these linkages are very simple to make, the problem with them is that the linkage forms a connecting rod between each pair of opposing bars, and this may give rise to problems of instability (figure 3 ). These linkages have been widely used in laboratory research (by Anouts et al., for example) as there is no need to adjust the bar ends [21]. The fins may be of considerable thickness, such as those suggested by Sang-Hoon and Popovic [22], or they may even include a hinged joint to facilitate deployment in some cases [19].

One widely used solution is to use linkages with concurrent axles but eccentric bar axes. One of the first solutions was the one successfully used by Escrig in the roof of San Pablo swimming pool, Seville (Escrig, Pérez-Valcárcel and Sánchez, 1996) [14]. The main problem with linkages of this type is the eccentricity introduced in the axial forces, which have to be taken into consideration in calculations [23]. To minimise this eccentricity, in San Pablo swimming pool duraluminium tubular bars were used, with fins at their ends welded in the centre of the section (figure 3). Roovers and De Temmerman propose a similar system, but with one fin that is lateral instead of central [19]. 

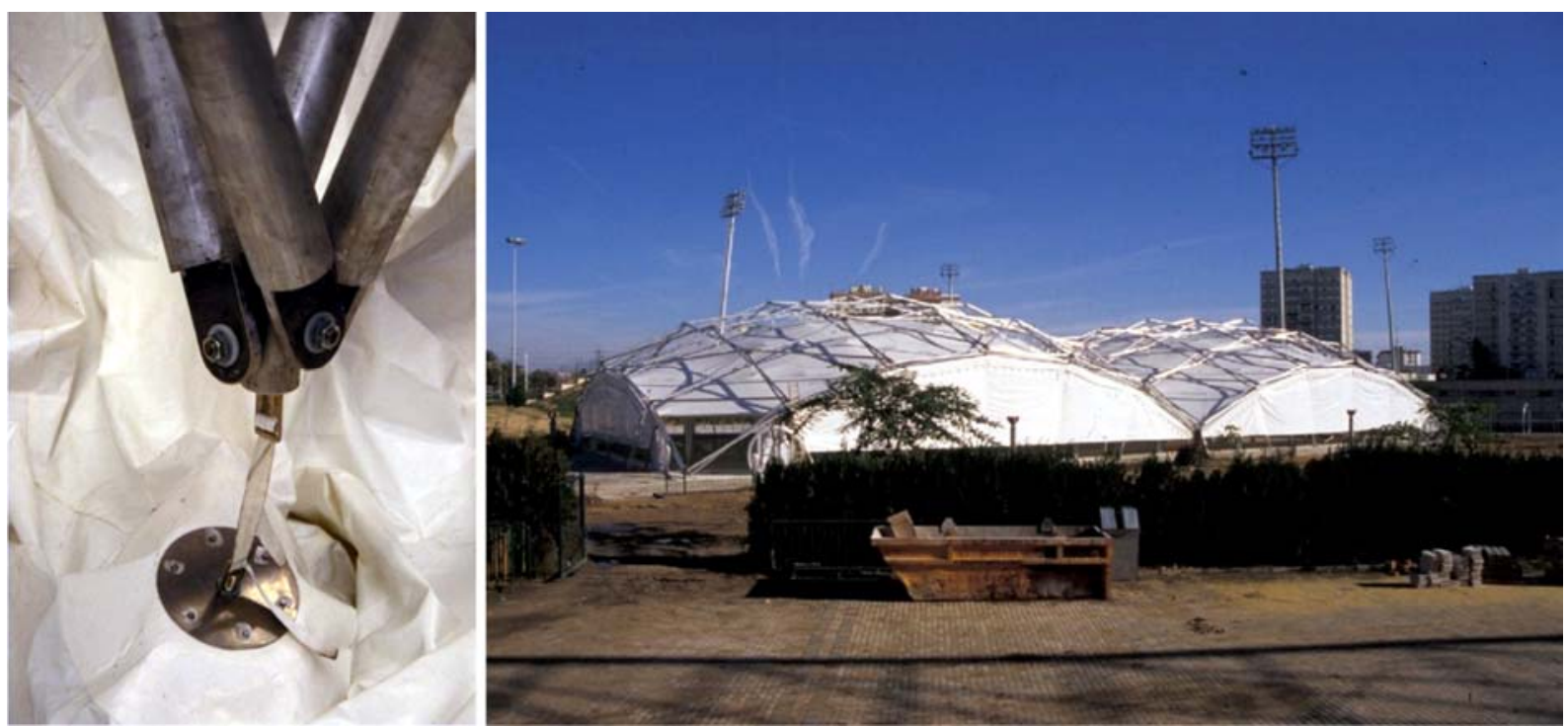

Figure 2.- San Pablo swimming pool: a linkage and the deployed roof.
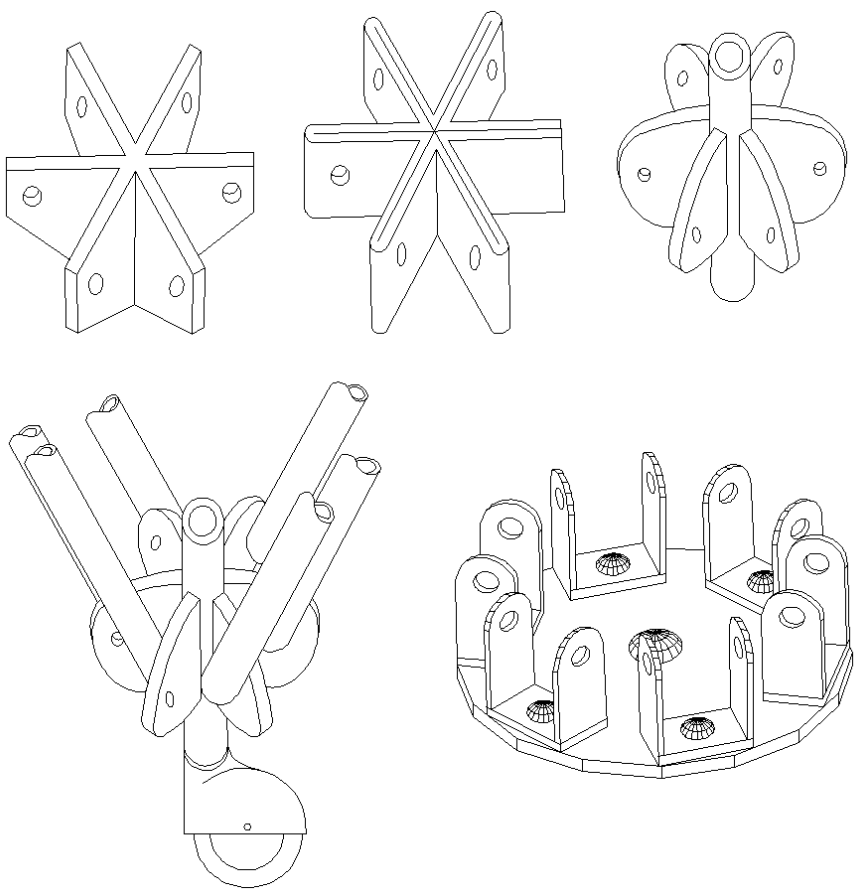

Figure 3.- Finned linkages. (Escrig 1988)

Finally, other proposals which use highly complex linkages also exist, and this aspect makes them unsuitable for the purpose of this research [24].

All of these linkages have one characteristic in common: the ends of the bars are joined to the linkage without any restriction in their movement, and this contributes to the major deformations suffered by the structures they create. This severely restricts their possible uses.

To improve these functions a new linkage is proposed. It is a very simple linkage composed of a metal ring, laterally bolted to the structural bars. The singularity of the design is that the bars are prolonged beyond the linkage, each one of them rests on the others, thereby forming a reciprocal structure. This gives rise to a major improvement in the mechanical behaviour of the expandable structure, most especially by restricting deformation. This idea is new within expandable structures design, as to date simple articulated joints had been used at the ends of the bars. These joints do not contribute in any way to reduce the deformability of the structure as a whole. This means that in general the bars must be bigger in cross-section to due to deformation than those which only have to resist forces. The proposed solution of reciprocal linkages significantly improves their behaviour. 
These reciprocal linkages make it possible a very high degree of embedding the end linkages. This leads to a major improvement in the performance of the structures, and even permits designs that would not be feasible with simply articulated linkages, as is the case with flat meshes which are mechanisms unless the nodes are blocked or additional bars are arranged. Conventional flat expandable structures are non-viable, in spite of their simplicity and versatility of use. There have been a few viable proposals, such as one for a flat mesh that effectively covers a sports track, with stiffening bars that are manually locked after expansion [25]. A patent was also proposed for a self-locking linkage that makes it possible to resolve this problem automatically [26]. These solutions are complicated and expensive. Nevertheless, the flat meshes developed using the proposed linkage require no additional bars after they have been expanded, given that the linkage itself restricts the movement of expansion. The linkage proposed here is far simpler and more effective for flat meshes (figure 4).
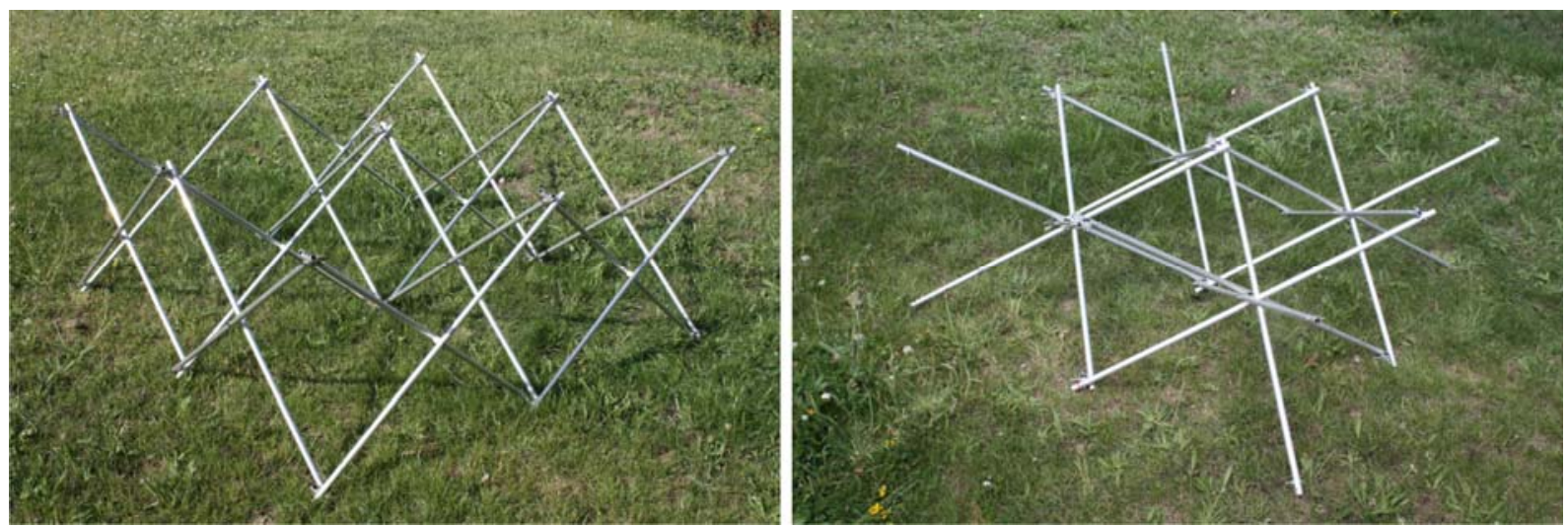

Figure 4.- Flat meshes of SLE and bundles with reciprocal linkages.

Many studies have also been undertaken in recent years of reciprocal systems, defined as: "The reciprocal frame is a three-dimensional grillage structure mainly used as a roof structure, consisting of mutually supporting sloping beams placed in a closed circuit. The inner end of each beam rests on and is supported by the adjacent beam. At the outer end the beams are supported by an external wall, ring beam or columns" [27]. The usual forms are the "arch-type" based on the design by Leonardo da Vinci for temporary bridges, and the "flat-type" inspired by Serlio for flat surfaces. The main problem with reciprocal linkages is the need to ensure an effective joint so that the bars do not slide over each other. The joints are usually executed on site, so that the construction of reciprocal structures is not especially fast.

The convergence of reciprocal and expandable structures and their emergency use has led to the study of reciprocal frames as easy and fast to construct [28]. Interesting solutions have been suggested recently that use reciprocal arches [29].

The solution which is proposed to avoid the above-mentioned problems combines the advantages of expandable and reciprocal structures. Expandability makes it possible to open and close the structure, making it compact and transportable. The reciprocal condition significantly increases the rigidity of the linkages. The structure is more stable when expanded and undergoes far smaller displacements, as will be seen.

\section{Description of the linkage.}

The system uses a linkage similar to the one used in expandable structures such as the roof of San Pablo swimming pool. This is a circular or square tubular element with bars that extend beyond it bolted onto its sides, so that when it opens they rest on each other to form a reciprocal structure (figure 5) [15].

The linkages at the ends of the bars cease to function as simple joints and attain a degree of rigidity similar to embedment. This makes the material more effective, with a considerable reduction in mesh displacement. On the other hand, it greatly simplifies the design of the linkages and the connection of the bars with the same. The result is a structure which performs better and is also simpler and cheaper [30]. 
The linkage is composed of a cylinder or prism that may be solid or hollow. Three pivots protrude from this in triangular meshes and four do so in square meshes, and the bars fit on to them (figure 5). In this specific case, linkages for four bars were used on a hollow square prism. Although both solutions are feasible, circular linkages are more resistant for wide span meshes, while square ones are simpler for models and small structures. Square linkages have a slight additional advantage, as they add a certain degree of restriction to the lateral movement of the bar, improving the rigidity of the structure.

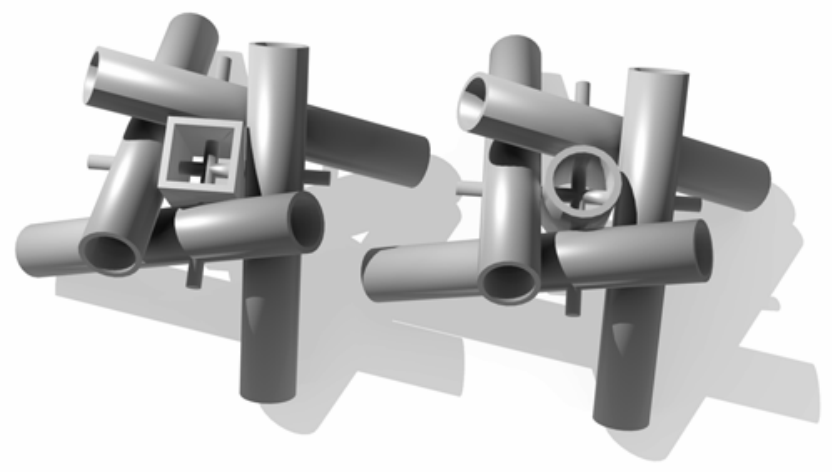

Figure 5.- Proposed reciprocal linkages for expandable structures.

The reciprocal pattern means that the linkage has to be strictly dimensioned according to the diameter of the linkage $D=2 R$, the diameter of bars $d=2 r$ and the desired angles of opening $\alpha, \beta$.

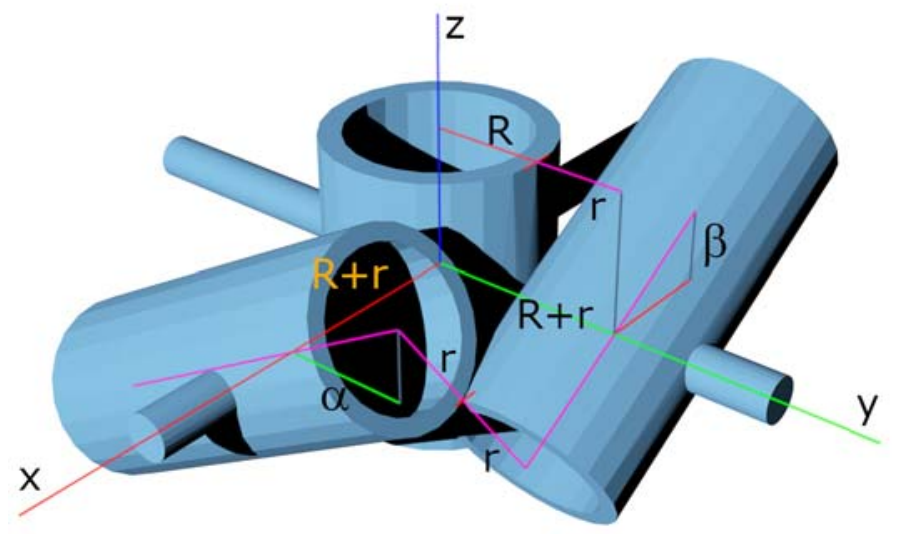

Figure 6.- Geometric relationship between diameters and opening angles.

Where $\mathbf{R}$ is the exterior radius of the linkage and $r$ is the radius of the bar, the axes of the bars are at a distance $\mathbf{R}+\mathbf{r}$ from the centre (figure 6 ). The straight lines $\mathbf{r}_{1}$ and $\mathbf{r}_{2}$, which correspond to the bar axes pass through points $\mathbf{A}_{1}$ and $\mathbf{A}_{2}$ and form the angles $\boldsymbol{\alpha}$ and $\boldsymbol{\beta}$ with the reference plane. Their unitary vectors are

$$
\vec{u}_{1}(0, \cos \alpha, \sin \alpha) \quad \vec{u}_{2}(-\cos \beta, 0, \sin \beta)
$$

Their points of passage are:

$$
A_{1}(R+r, 0,0) \quad A_{2}(0, R+r, 0)
$$

The distance between two straight lines that cross is the mixed product, divided by the vector product modulus. This distance is $\mathbf{2} \mathbf{r}$, as the bars are assumed to touch at the point of contact.

$$
\begin{gathered}
2 r=\frac{\left|A_{1} A_{2} \cdot \vec{u}_{1} \cdot \vec{u}_{2}\right|}{\left|\vec{u}_{1} \times \vec{u}_{2}\right|}=\frac{(R+r) \cdot \sin (\alpha+\beta)}{\sqrt{\sin ^{2} \alpha \cdot \cos ^{2} \beta+\cos ^{2} \alpha \cdot \sin ^{2} \beta+\cos ^{2} \alpha \cdot \cos ^{2} \beta}} \\
\frac{D}{d}=\frac{2 \cdot \sqrt{\sin ^{2} \alpha \cdot \cos ^{2} \beta+\cos ^{2} \alpha \cdot \sin ^{2} \beta+\cos ^{2} \alpha \cdot \cos ^{2} \beta}}{\sin (\alpha+\beta)}-1
\end{gathered}
$$




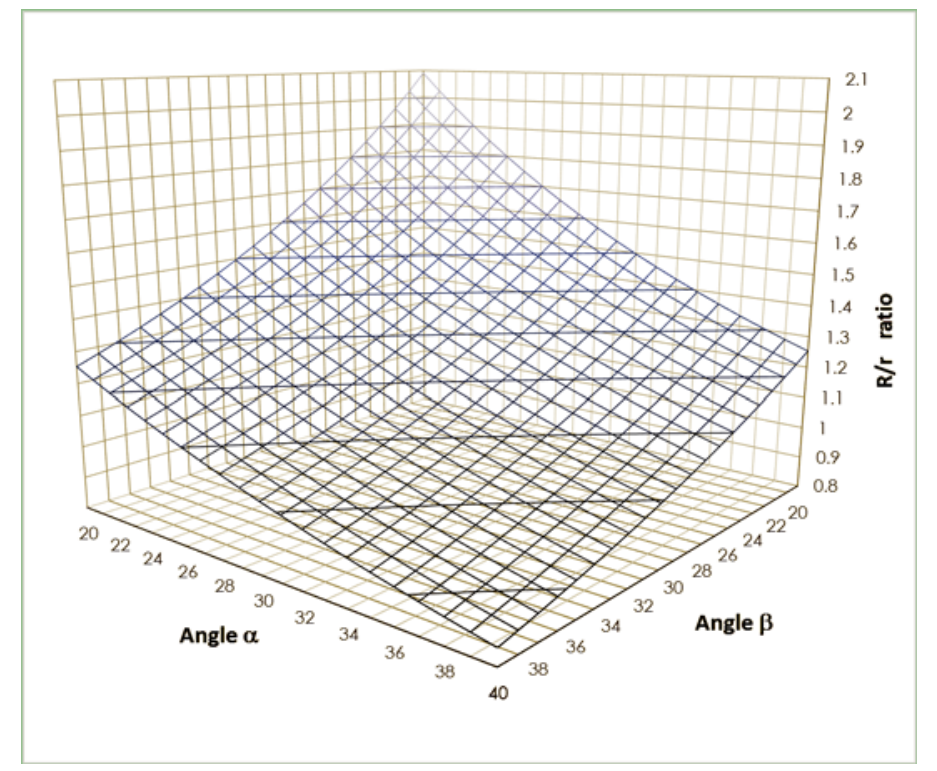

Figure 7.- Graph of the relationship between diameters and opening angles.

This equation makes it possible to determine the diameter $\mathbf{D}$ which the linkage must have so that $\mathrm{d}$ diameter bars are able to open to the specific angles $\alpha$ and $\beta$. This is the most general case and it arises in highly useful structures such as cylindrical vaults. The results are shown in figure 7.

In flat meshes and regular domes both angles are equal. The formulae are simpler in this case [2]

$$
\frac{D}{d}=\frac{\sqrt{1+\sin ^{2} \alpha}}{\sin \alpha}-1
$$

The results in this particular case are shown in Table 1.

Table 1.- Relationship between the proportion of diameters and the opening angle.

$\begin{array}{llllllllllll}\text { D/d } & 1.0 & 1.1 & 1.2 & 1.3 & 1.4 & 1.5 & 1.6 & 1.7 & 1.8 & 1.9 & 2.0 \\ \text { Angle }\left(^{\circ}\right) & 35.26 & 32.79 & 30.68 & 28.87 & 27.20 & 25.88 & 24.62 & 23.50 & 22.48 & 21.55 & 20.70\end{array}$

For practical purposes reciprocal linkages with different angles are used in cylindrical surfaces, while those with the same angles are used in flat meshes or spherical surfaces.

$\left.\right|_{+} ^{\circ}$

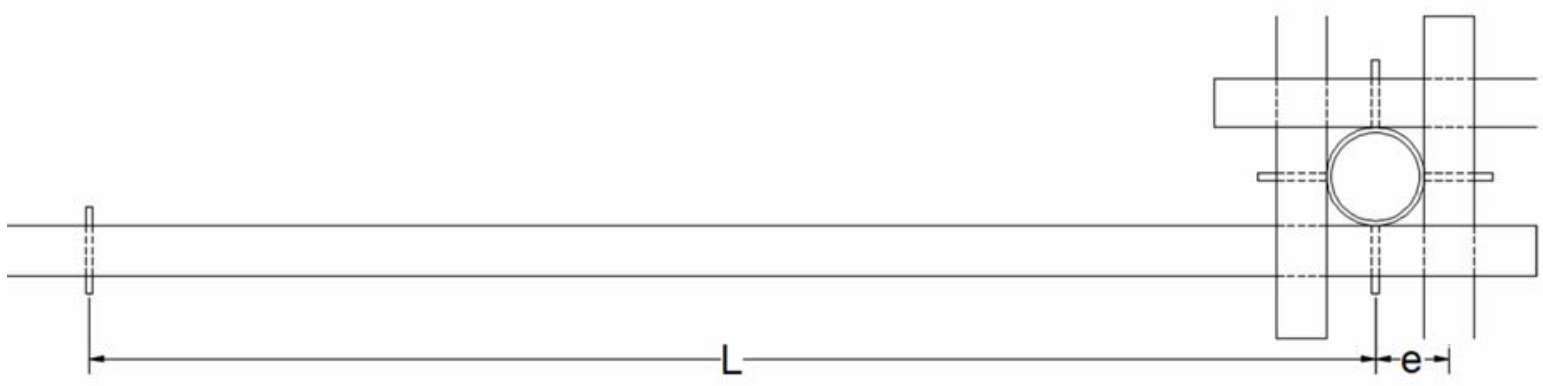

Figure 8.- Reciprocal support geometry.

A reciprocal connection works in almost the same way as a unilateral embedment. The bar end rests on the pin that joins it to the linkage and on the closely adjacent bar, so that the turn is very small and almost zero. It is elemental to calculate the embedment factor by applying Mohr's theorems. Terming the distance from the pin to the resting point $\mathbf{e}$ and $\mathbf{L}$ the length of the bar until the inner joint, gives $a$ simple formula [3] for calculating the degree of embedment $\mathbf{g}_{\mathbf{e}}$, understood as the ratio between the moment transmitted to the linkage and what would be obtained if the said linkage were embedded. 


$$
g_{e}=\frac{L}{L+e}
$$

\section{Materials and methods.}

The core aim of this paper is to check the viability and efficacy of the proposed linkages, in isolation as well as when they are included in a mesh. Firstly, the behaviour of a simple flat mesh was analysed, and it was found to lack rigidity in the linkage articulations. Different tests were then performed on small models, to assess the efficacy of the system, and these tests are described below.

Once the effectiveness of the linkage was verified and before analyzing the behaviour of real structure, the study of a single joint was carried out to discover the degree of embedding that can really be achieved. A set of tests was therefore prepared with the aim of testing the performance of structures in depth, before proceeding to analyse the complete structure, as will be described in subsequent works.

\subsection{Materials}

The bars in all test models are of type 6060 aluminium (aluminium - magnesium - silicon) in state T5 (figure 8). Their mechanical characteristics are:

$\begin{array}{ll}\text { Modulus of elasticity } & 69500 \mathrm{~N} / \mathrm{mm}^{2} \\ \text { Failure load } & 220 \mathrm{~N} / \mathrm{mm}^{2} \\ \text { Elastic limit } & 185 \mathrm{~N} / \mathrm{mm}^{2} \\ \text { Specific weight } & 2700 \mathrm{kN} / \mathrm{m}^{3}\end{array}$

The bolts are 5.6 quality according to ISO $898-1$, with the following properties

$\begin{array}{ll}\text { Failure load } & 500 \mathrm{~N} / \mathrm{mm}^{2} \\ \text { Elastic limit } & 300 \mathrm{~N} / \mathrm{mm}^{2} \\ \text { Elongation \% } & 20\end{array}$

\subsection{Models}

Two types of model were constructed to test the viability of the linkages. On the one hand two flat deployable meshes were constructed to test the efficacy of the linkage under real conditions of use. On the other hand, 12 specimens were made of a linkage with 4 L-shaped bars, to check the behaviour of the linkages until failure.

\subsubsection{Models for deployable meshes}

The flat meshes that were tested are composed of four bladed modules. One of the models was made using articulated linkages, and another was made with the new reciprocal linkages. Simple comparison of both models showed that the reciprocal linkages were clearly better. The mesh of articulated linkages behaved as a mechanism, while the one composed of reciprocal linkages deployed before stabilising in its final position without any type of auxiliary elements.

To compare both modules it was necessary place four bracing bars in the corners of the mesh, to stabilise its shape and enable it to withstand loads. Tests were also performed using the mesh of reciprocal linkages with identical bracing bars in its corners, so that they could be performed under the same conditions with results that could be compared.

Both flat deployable meshes are $56 \mathrm{~cm}$ high and with a modular width of $75.5 \mathrm{~cm}$ (figure 4a). The bars are in $16 \mathrm{~mm}$ diameter $1.9 \mathrm{~mm}$ thick 6060-T5 aluminium, and the additional bars are $13 \mathrm{~mm}$ diameter and $1.5 \mathrm{~mm}$ thick. The nodes are squares of the type described in Figure $5 \mathrm{~b}$. They are formed of a square aluminium hollow section of the same quality, with $20 \mathrm{~mm}$ sides $20 \mathrm{~mm}$ in height and $1.4 \mathrm{~mm}$ thick. The pivots are composed of $\varnothing 4 \mathrm{~mm}$ threaded and centrally welded steel rods of the quality indicated in 3.1.

\subsubsection{Models for linkage testing}

Regarding the linkages tests, a total of 12 specimens were constructed to verify the validity of the proposed solutions. Each one was composed of four aluminium bars joined on to a cross-shaped linkage. When the linkage moved each bar rested on the next one, forming a reciprocal connection. This made it possible to simultaneously restrict the opening as well as the turning of the bar when in the expanded position. Its mechanical behaviour is similar to that of embedment. 
The bars are $16 \mathrm{~mm}$ in diameter and $1.9 \mathrm{~mm}$ thick. The linkage was composed of four $3 \mathrm{~mm}$ steel bolts with their heads welded together, forming a cross. The heads were then filed down to make it possible for the load to rest on it correctly. The hole is $4 \mathrm{~mm}$ in diameter. The bars were placed at a suitable distance so that the reciprocal support occurred simultaneously in all four bars, to prevent distorting the results.
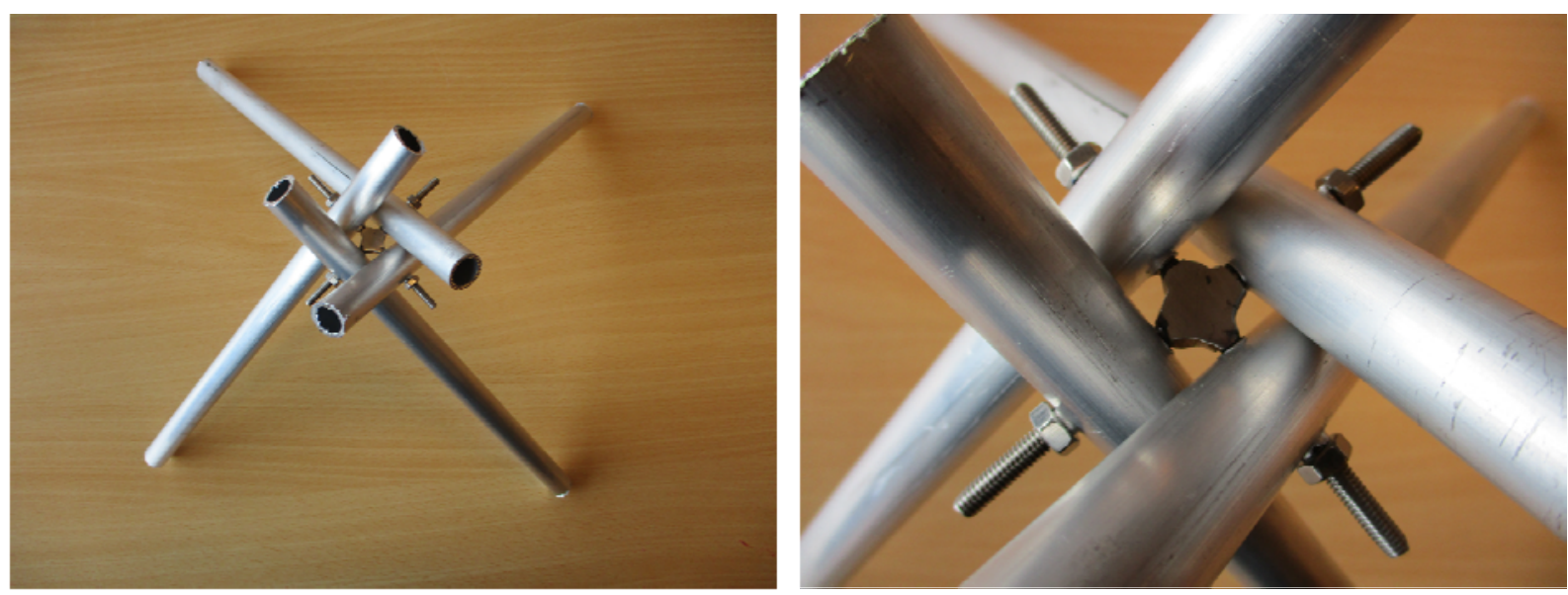

Figure 9.- Test specimens.

The bars in the model are $300 \mathrm{~mm}$ long, with a hole at $50 \mathrm{~mm}$ from the end. They are arranged pyramidally with a base $280 \times 280 \mathrm{~mm}$ between bar axes and a height of $155 \mathrm{~mm}$ between the axes of the linkage and the axes of the supports of the bars. The angle is $\alpha=38.216^{\circ}$ and the proportion between the diameter of the linkage and the diameter of the bar is 0.8977 , so that the linkage diameter is $14.36 \mathrm{~mm}$. To achieve correct reciprocal support between the four bars in the model, it is necessary for the distances from the centre to be exact, given that the angle depends on the ratio between the diameter of the linkage and the diameter of the bar. To achieve this, a wooden template was made, after which the models were placed on it and the bolts were adjusted until all four bars in the models were simultaneously supported. The exact distance must be adjusted by the nuts. The model was checked to ensure that the theoretical proportions were suitably expressed.

\subsection{Tests}

\subsubsection{Models for deployable meshes}

Each one of the meshes that were constructed with articulated or reciprocal linkages was subjected to three tests. Bracing bars were fitted to the corners in both cases. The tests were conducted using the A Coruña ETS Arquitectura test bed. The meshes were supported at their corners on HDPE plates to minimise friction, and they were loaded with $510 \mathrm{kgf}(98.1 \mathrm{~N})$ weights placed on the central linkage and in the centres of the sides, on the upper layer. Displacements were measured using Schreiber Sm407.100.2.T inductive displacement sensors with a lineality $<0.25 \%$ and deviation $<0.01 \% /{ }^{\circ} \mathrm{C}$. Data recording was completed with Y103 digital extensometers with a precision of $\pm 0.1 \mathrm{~mm}$. Displacements were measured at the centre of the mesh and in one of its edges.

Firstly, a previous step of loading was applied to adjust the linkages. This aspect is more important in deployable structures: as they are mobile, it is necessary for their joints and linkages to have a certain tolerance. When load is applied to the structure it adjusts and undergoes a certain initial displacement. After removal of the initial load the structure largely maintains its adjusted position, although there is a slight recovery. When the second load is applied the structure deforms accordingly. This is indispensable to validate calculation methods using experimental results.

\subsubsection{Models for linkage testing}

Two series of tests were conducted to check the validity of the proposed solutions: one series with free support and the other with a constrained support. Each series was composed of 6 specimens which were loaded until the model failed. Both types of support were tested because theoretical models indicated that failure would arise in the case of free support due to crushing of the bars, much earlier than failure of the linkage. On the other hand, failure would arise with constrained support due to crushing and turning of the linkage followed by crushing of the bars. The test machine uses the MKS system of units and therefore the test data will be indicated in this system. 

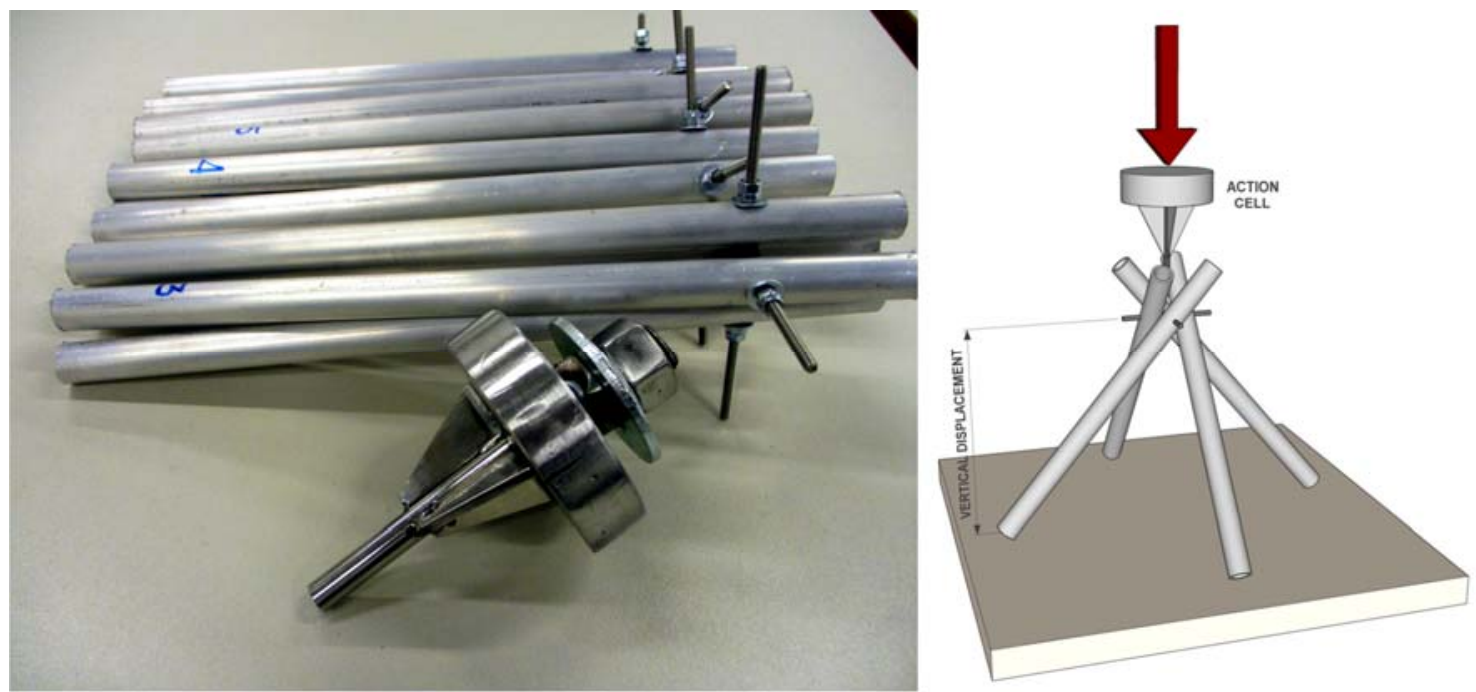

Figure 10.- Load piece and scheme of load transmission.

The tests were performed using a 20 Tf Omadisa bending test machine. This has a span of $600 \mathrm{~mm}$ between its supports and a run height of $220 \mathrm{~mm}$, which is suitable for the tests in question. The load is applied by a $2 \mathrm{Tf}=196.2 \mathrm{kN}$ loading cell, which is sufficient for the tests. The load is transmitted by a $10 \mathrm{~mm}$ diameter metal cylinder that is bolted to the upper plate of the press. Three fins were welded to the piece under load for the support tests to increase rigidity. This assembly is shown in figure 10. The machine allows to regulate the drive speed between $0.1 \mathrm{~mm} / \mathrm{min}$. and $100 \mathrm{~mm} / \mathrm{min}$. and between $0.1 \mathrm{Kp} / \mathrm{s}$ and $1,000 \mathrm{Kp} / \mathrm{s}$. The load is applied through a load cell with a precision of $0.05 \mathrm{Kp}$ $=4.9 \mathrm{~N}$. It has a displacement sensor with a resolution of 15000 steps $/ \mathrm{mm}$. The results of applied force and displacement are collected by means of a specific program that allows their subsequent processing.

In the free support tests the models were simply supported on a $400 \times 400 \times 10 \mathrm{~mm}$ steel plate (figure 11a). For the constrained support tests four $30.3 \mathrm{~L}$-shaped pieces were welded onto the plate to support the ends of the bars, preventing them from sliding (figure 10b).

All of the tests were performed by taking the force applied as the control variable. In the freely supported tests the test velocity was $3.3 \mathrm{kgf} / \mathrm{s}$. An upper limit was set for the force of $200 \mathrm{kgf}$, with a sampling interval of $1.00 \mathrm{~s}$.

In the constrained support tests the test velocity in the loading cycle was $3.3 \mathrm{kgf} / \mathrm{s}$. An upper limit was set for the force at $1000 \mathrm{kgf}$ with sampling intervals of $1.00 \mathrm{~s}$. When failure occurred a controlled unloading cycle was performed at a velocity of $10 \mathrm{kgf} / \mathrm{s}$.
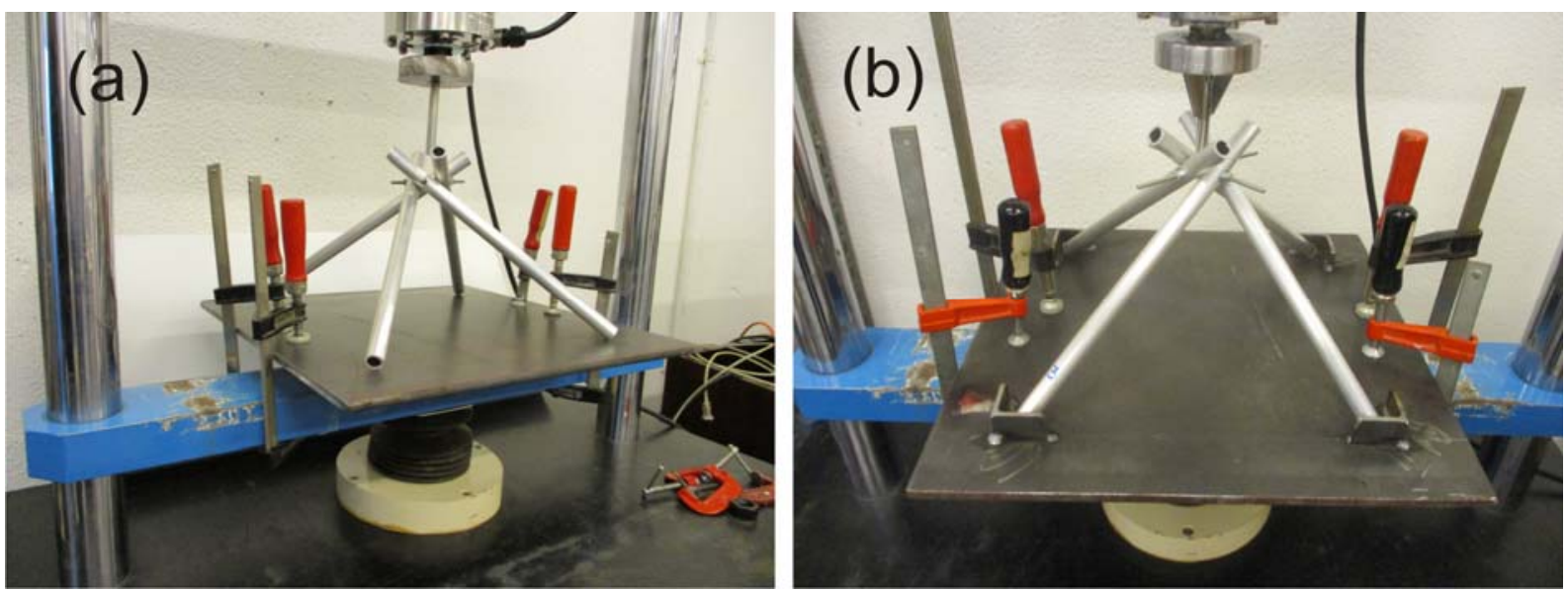

Figure 11.- Tests for specimens with sliding and fixed ends. 


\section{Results.}

\subsection{Numerical analysis}

To analyse the deployable meshes numerically the models tested were calculated using the Rigid 3.06 program, which uses matrix structural analysis. The program assigned a degree of embedding to the linkages at the ends of the bars, and this was entered as a datum. The program considered the interior linkages of the bars to consist of sliding connections: it considered the displacements of both points connected to the linkage to be equal, although the bars are able to turn freely along the plane of the blade. With the stated dimensions the degree of embedding of the reciprocal linkages amounts to $97.55 \%$.

To evaluate the results of the linkage tests, the theoretical results obtained in the model calculated using FEM were analysed. A direct approach was used in a 3D FEM model using the Ansys Workbench Academic Research V.18 program. Numerical analysis aims to evaluate the predictive capacity of the model regarding the behaviour obtained in laboratory tests.

The aluminium tubes were modelled using 3D volume elements and they were meshed using 20 node SOLID186 elements, with three degrees of freedom per node. The steel elements combine SOLID186 elements with SOLID187 elements, defined by 10 nodes with three degrees of freedom and suitable for modelling irregular meshes.

The model reproduces the behaviour of a system of interconnected bodies equipped with articulation elements that permit a suitable degree of kinematic restriction of the relative movement of the bodies within the articulation. The model uses MPC184 set elements, defined by two nodes with 6 degrees of freedom in each node. The kinematic restrictions of the set elements are imposed using the Lagrange multiplier method. The model combines these joints with CONTA174 to represent contact between the target 3D surface (TARGE170) with a contact algorithm based on the Augmented Lagrange Method.

A non-lineal 20 step increased load analysis was developed, giving results in terms of tension distribution, deformation and the state of contact using the contact tool option.

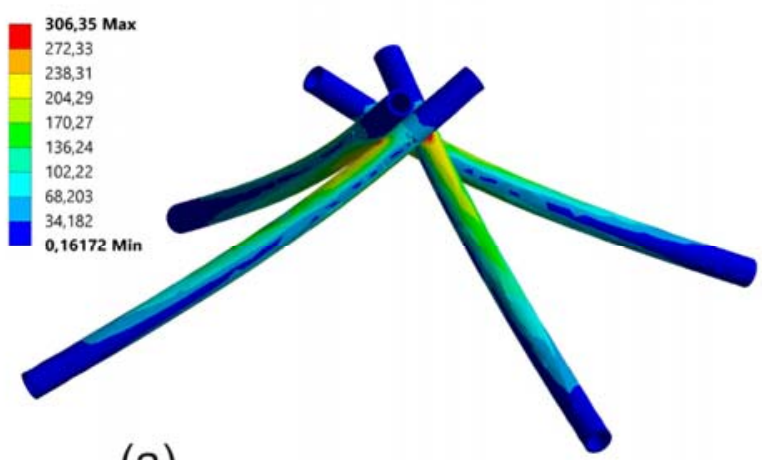

(a)

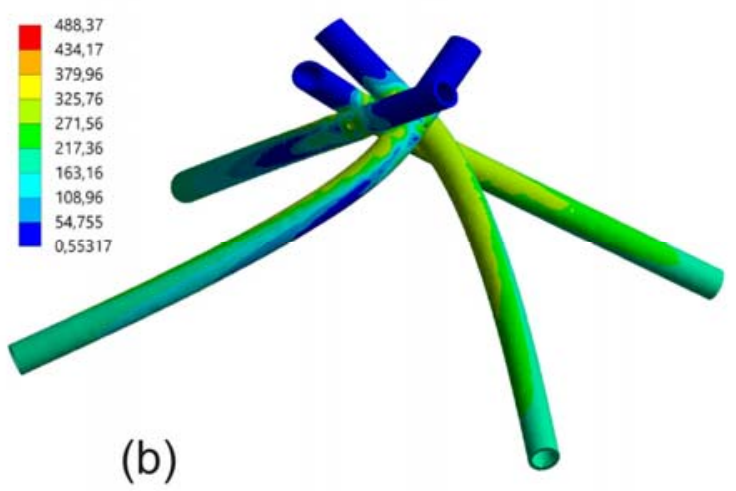

(b)

Figure 12,- Von Mises' stresses in MPa for specimens with sliding (a) and fixed ends (b).

The maximum load considering the elastic limits of the steel and aluminium would occur for a total load of $5.48 \mathrm{kN}$, considering that the linkage would deform plastically before the bars. Given these considerations this value is taken solely as an approximation, as several different plastifications occurred at this load level, in the linkage as well as in the bars. Failure at maximum load would be at $8.86 \mathrm{kN}$, estimated as the load which causes unacceptable stresses throughout the section. These limits were used as the reference for all of the specimens.

The first specimen behaved far better than had been foreseen. The maximum load surpassed $10 \mathrm{kN}$, so that the automatic reduction occurred once the planned limit had been exceeded. When the test model was analysed it was found that the linkage had turned within its plane, forcing an almost perfect bend in the bars. Everything indicates that the load had centred totally symmetrically, and this explains the high value obtained.

On the contrary, the other specimens behaved in a far more foreseeable way. The results indicate major bending of the linkage bolts and complete crushing of the bars. The results are slightly inferior to the theoretical model, probably because of slight eccentricities in the application of the load. The results for all of the specimens are very similar, so that they are considered to be a reasonable limit for practical purposes. The only curve that differs from the others corresponds to specimen 2 , in which as 
crushing occurred continuously there was no sudden fall in the load. Due to this the machine continued to move until the test was interrupted manually.

\subsection{Experimental analysis}

\subsubsection{Model for deployable meshes}

The tests were carried out by applying the load progressively using the aforementioned load test bed. For each type of mesh a first test to adjust the structure was carried out, followed by two tests from which the displacement measurements were taken. The results obtained are shown in table 2.

Table 2.- Displacements of deployable meshes

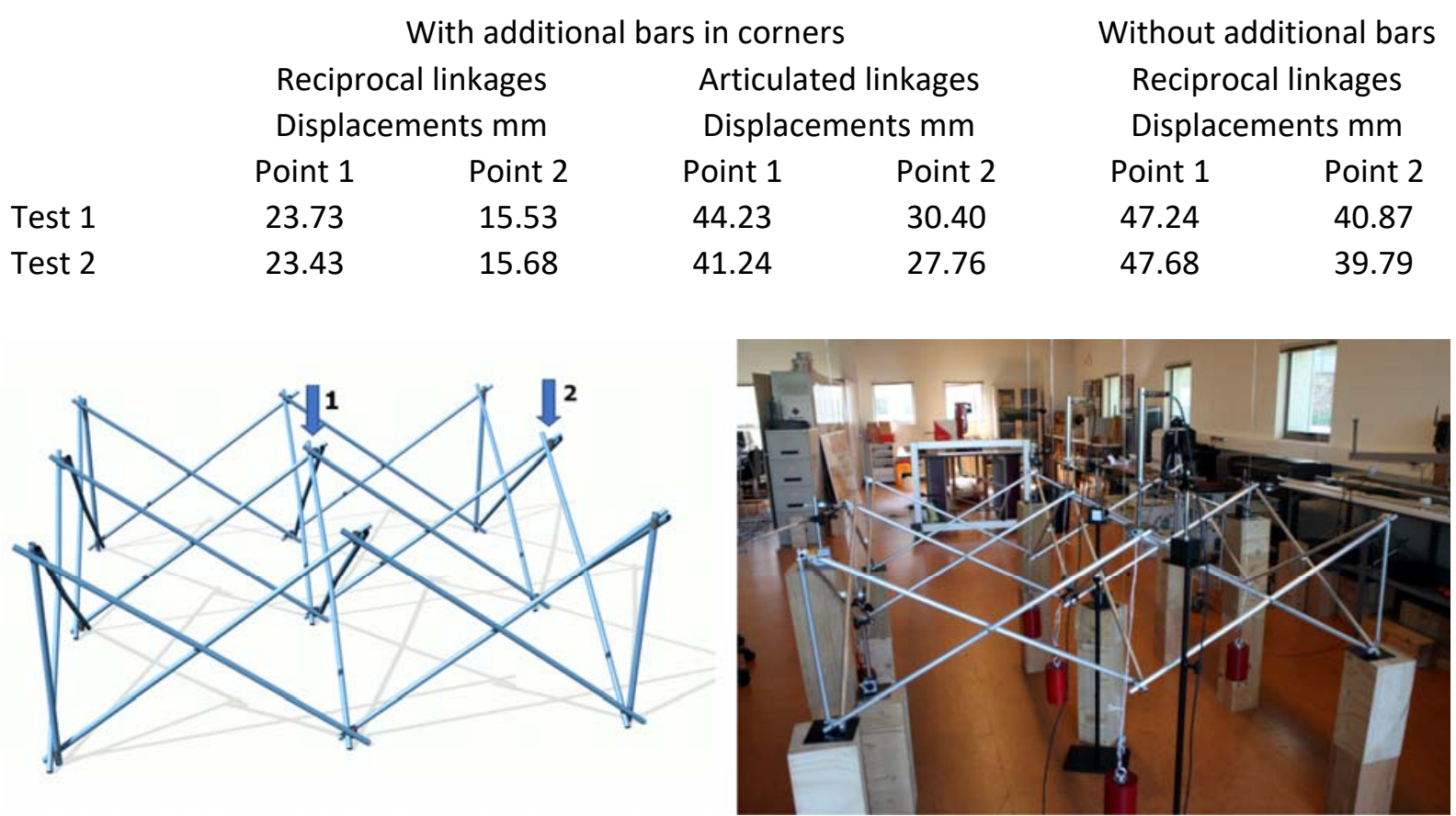

Figure 13.- Testing the flat deployable mesh, showing the position of the displacement sensors.

4.2.2 Model for linkages with sliding ends

In this case a test with six different specimens of the described model was carried out. The specimens rested on the support place and their ends were able to move freely. The first two tests continued until the machine stopped automatically. In the following fours tests deformation was restricted to $50 \mathrm{~mm}$, as the behaviour detected was understood to be very regular. The following graph [11] shows the results obtained. 


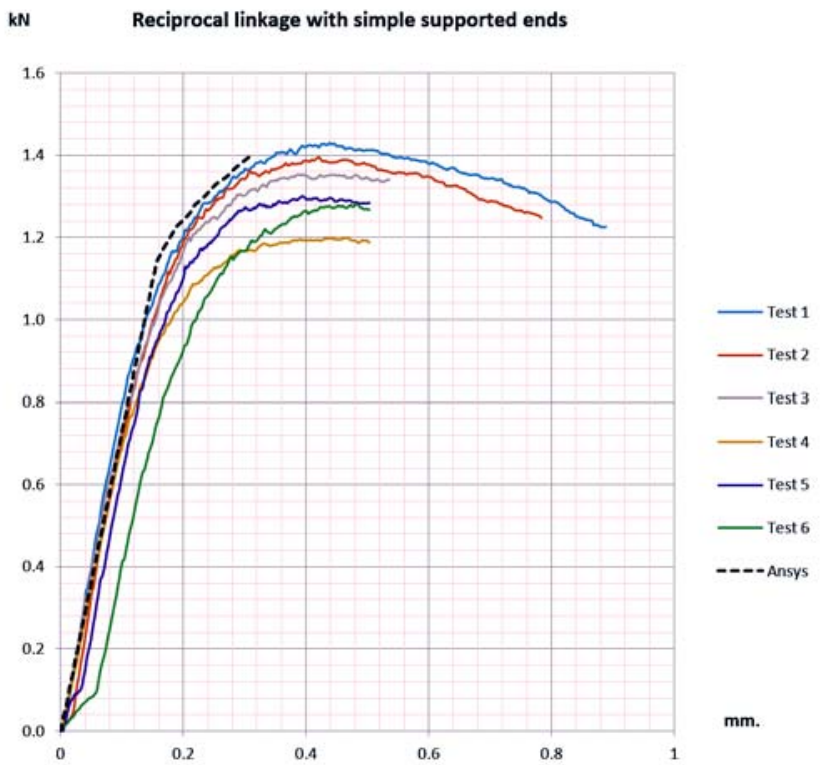

Figure 14.- Force/displacement graphs for models with sliding ends

Expandable structures require tolerance in their linkages to allow deployment and folding movements. Due to this, there is always an initial adjustment displacement when a load is applied, and once the model has adjusted then elastic and plastic displacements occur. In the first case (models with sliding ends) the greatest displacements occurred in specimens 6 and 4, while in both of these cases their subsequent behaviour fitted the foreseen pattern.

The theoretical behaviour of a specimen composed of the set of four bars was analysed to evaluate the above results. To define the reference values, we considered the linkage to be formed of reciprocally supported bars. The experimental results prove that collapse occurs due to bending of the bars. The stresses in the bars under flexion reach the elastic limit of aluminium, $185 \mathrm{~N} / \mathrm{mm}^{2}$, at a load of $1007.98 \mathrm{~N}$. The stress reaches the failure limit of $200 \mathrm{~N} / \mathrm{mm}^{2}$ at a load of $1198.66 \mathrm{~N}$. These values are taken as the reference for these tests (table 2).

Table 3.- Results for models with simple supported ends and comparison with theoretical ones.

\begin{tabular}{lllll}
\multirow{2}{*}{ Specimen } & \multicolumn{3}{l}{ Elastic limit } & \multicolumn{2}{l}{ Failure limit } \\
\cline { 2 - 5 } & Measured load N & Deviation & Measured load N & Deviation \\
\hline 1 & 1143.94 & $11.89 \%$ & 1397.53 & $14.23 \%$ \\
2 & 1163.86 & $13.39 \%$ & 1368.40 & $12.40 \%$ \\
3 & 1106.18 & $8.88 \%$ & 1325.82 & $9.59 \%$ \\
4 & 1039.76 & $3.06 \%$ & 1176.22 & $-1.91 \%$ \\
5 & 1112.26 & $9.38 \%$ & 1272.26 & $5.78 \%$ \\
6 & 1032.89 & $2.41 \%$ & 1255.39 & $4.52 \%$
\end{tabular}

The graphs show no clear elastic limit, so that the stress corresponding to a deformation of $2.66 \%$ o has been assumed to be this limit, and this corresponds to the characteristics of the aluminium tested. 


\subsubsection{Model with constrained ends}

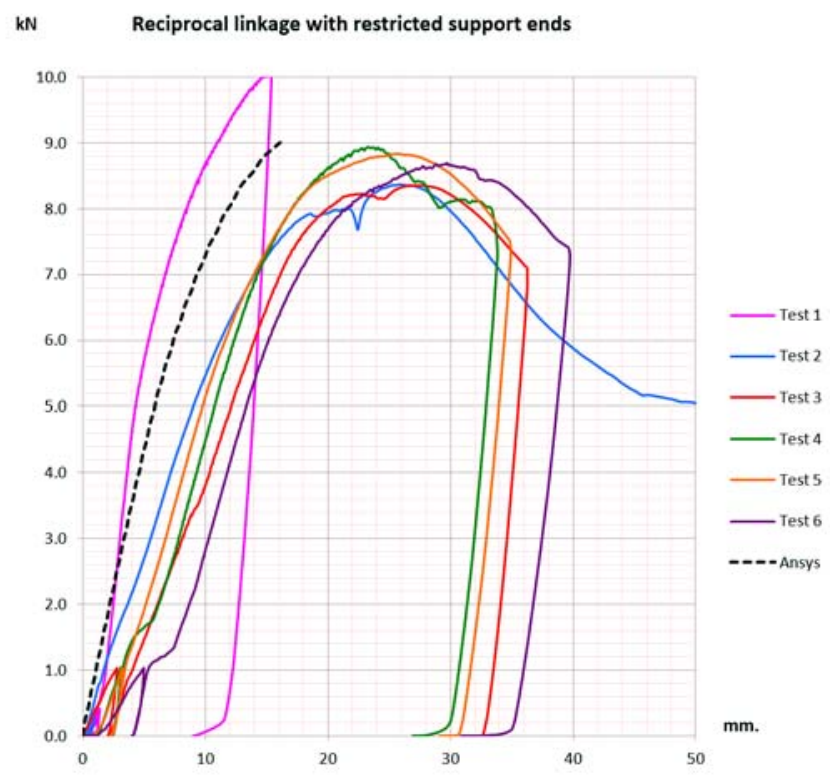

Figure 15.- Force/displacement graphs for models with constrained ends

In the second case (models with restrained ends), the planned loads were far greater than those in the previous tests, so that the test system was modified. To achieve an effective adjustment, the test machine was programmed to carry out an initial cycle with a load of $50 \mathrm{kgf}$ in the case of tests 1 and 2 . In the four remaining tests the initial load was raised to $100 \mathrm{kgf}$. The load was then completely removed, followed by a new loading cycle until failure. Given that the theoretical results indicated a maximum load of $900 \mathrm{kgf}$, the upper load limit was set at $1000 \mathrm{kgf}$. When failure occurred a controlled cycle of load removal was carried out at a velocity of $10 \mathrm{kgf} / \mathrm{s}$

Table 4.- Results for models with constrained ends and comparison with theoretical ones.

\begin{tabular}{lllll} 
& \multicolumn{3}{l}{ Elastic limit } & \multicolumn{3}{l}{ Failure limit } \\
\cline { 2 - 5 } Specimen & Measured load kN & Deviation & Measured load kN & Deviation \\
\hline 1 & 85.15 & $35.64 \%$ & 9.86 & $10.16 \%$ \\
2 & 55.23 & $0.78 \%$ & 8.21 & $-7.94 \%$ \\
3 & 51.40 & $-6.61 \%$ & 8.19 & $-8.13 \%$ \\
4 & 58.76 & $6.74 \%$ & 8.76 & $-1.07 \%$ \\
5 & 62.59 & $12.44 \%$ & 8.67 & $-2.20 \%$ \\
6 & 53.96 & $-1.57 \%$ & 8.53 & $-3.89 \%$
\end{tabular}

\section{Discussion.}

Firstly, the efficacy of the proposed linkage in limiting mesh deformations should be underlined. It was observed that displacement of the upper central linkage fell to values from $52.97 \%$ to $57.54 \%$. For an upper edge linkage the fall in displacement in the reciprocal linkage mesh stands at from $51.58 \%$ to $55.94 \%$. This type of mesh is quite unfavourable, given that only two linkages of 18 are totally braced. In meshes with a higher number of modules the fall in displacements is sure to be greater.

The same mesh with reciprocal linkages was also tested without the additional bars at the corners. This type of mesh could not be constructed with articulated linkages, as it would be a mechanism. It was observed that the displacements measured amount to $47.68 \mathrm{~mm}$ for the central linkage and 40.87 $\mathrm{mm}$ in the upper edge linkage, corresponding to an increase of $103 \%$ and $160 \%$, respectively, in comparison with the model with additional bars in the corners. These bars have a great effect, indicating that the use of reciprocal linkages is highly effective in increasing the rigidity of deployable structures and reducing their deformations. Several tests were performed with other types of mesh, and these support the efficacy of reciprocal linkages and will be described in subsequent papers. 
The study of the linkages aimed to determine their strength. To check the performance of the linkages, two types of tests were carried out, with sliding ends and with fixed ends. In the first case, models with simply supported extremes, observed behaviour is very similar to that predicted theoretically. Failure in all cases is caused by crushing bars and no damage is seen in the linkage. This is the situation that actually occurs in real deployable structures, so the results of these tests are particularly useful.

The second case, which corresponds to the nodes fixed at their ends, was designed to analyze behaviour of linkages until failure. To evaluate these results, the theoretical results obtained in the model calculated using FEM were analysed. The maximum load considering the elastic limits of the steel and aluminium would occur at a total load of $5.48 \mathrm{kN}$, considering that the linkage would deform plastically before the bars. Given these considerations this value is taken solely as an approximation, as several different plastifications occurred at this load level, in the linkage as well as in the bars (figure 15). Failure at maximum load would be at $8.86 \mathrm{kN}$, estimated as the load which causes unacceptable stresses throughout the section. These limits were used as the reference for all of the specimens.

The first specimen behaved far better than had been foreseen. The maximum load surpassed 1000 kgf, so that automatic reduction occurred once the planned limit had been exceeded. When the test model was analysed it was found that the linkage had turned within its plane, forcing an almost perfect bend in the bars. Everything indicates that the load had centred totally symmetrically, and this explains the high value obtained.

On the contrary, the other specimens behaved in a far more foreseeable way. The results indicate major bending of the linkage bolts and complete crushing of the bars. The results are slightly inferior to the theoretical model, probably because of slight eccentricities in the application of the load. The results for all of the specimens are very similar, so that they are considered to be a reasonable limit for practical purposes. The only curve that differs from the others corresponds to specimen 2 , in which as crushing occurred continuously there was no sudden fall in the load. Due to this the machine continued to move until the test was interrupted manually.

A reciprocal connection functions like an articulated linkage with a certain degree of embedment. Theoretical models indicate that this embedment is always very high. In the model tested, applying the equation [3], it would amount to $93.98 \%$, as the bars are quite short, although in actual structures the degree of embedment is usually above $95 \%$. For the purposes of a comparative study, the reciprocal linkage has been considered with its degree of embedment, which sets an upper limit to the strength of the linkage.

Failure modes occurred according to what had been predicted in the theoretical models. In the case of free support collapse occurred due to crushing of the bars. The linkage was not damaged in any of the tests. The forces measured within the elastic limits are always superior to those which were calculated theoretically, at percentages from $2.41 \%$ to $11.89 \%$. This may be explained by the fact that no permanent deformations occurred in the bars within the elastic domain, and the elastic limit of the actual bars is always higher than the theoretical limit.

In the collapse situation, the results of testing simply supported models indicate that the majority of experimental results are better than the theoretical ones. Only in test 4 was a slight reduction detected of $1.87 \%$ in failure loads. In this case slightly asymmetrical crushing of the bars occurred, probably due to a slight eccentricity in how the load was applied. 


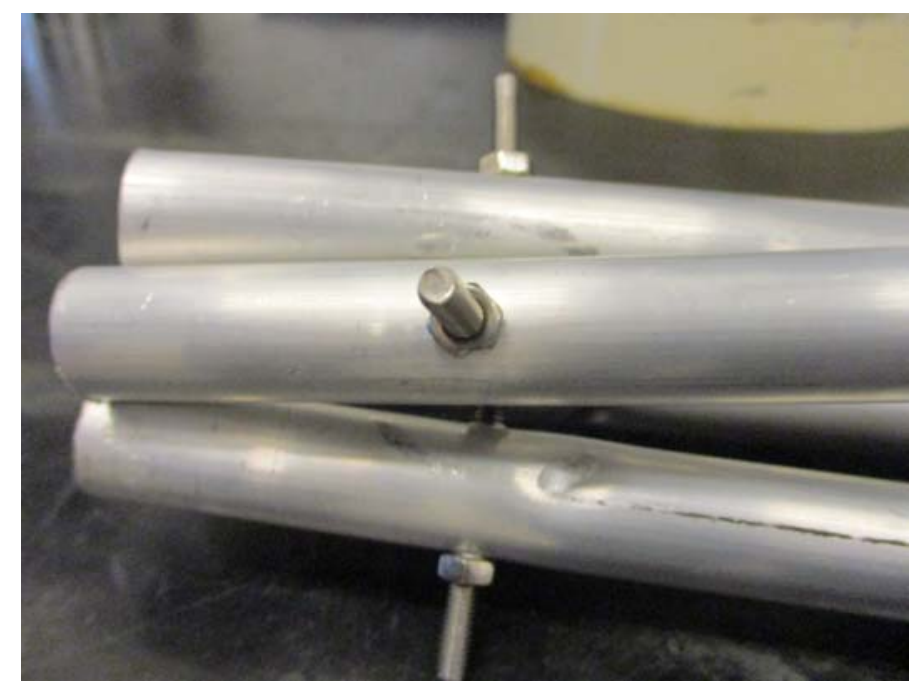

Figure 16.- Failure pattern for linkages with simple supported ends

In the models with constrained supports collapse occurred due to crushing, and the linkage suffered major damage. The bars were crushed due to the failure of the linkage, although this crushing was not critical until the latter had collapsed.

The results of tests in models with constrained support indicate two possible types of failure. In one case, such as specimen 1, failure occurred due only to horizontal bending of the threaded rods in the linkage. The bars were bent more strongly although without becoming completely crushed. The linkage withstood a force $10.16 \%$ greater than the theoretically predicted force. Analysis of this failure showed that the load had been transmitted in an exceptionally centred way. On the contrary, the other specimens collapsed because of combined failure of linkage bending and bar crushing. The failure load values obtained run from $92.64 \%$ to $98.93 \%$ of the load predicted by the theoretical model. These results are considered more realistic, given that in actual structures it is impossible to achieve such exactitude in centring the loads.
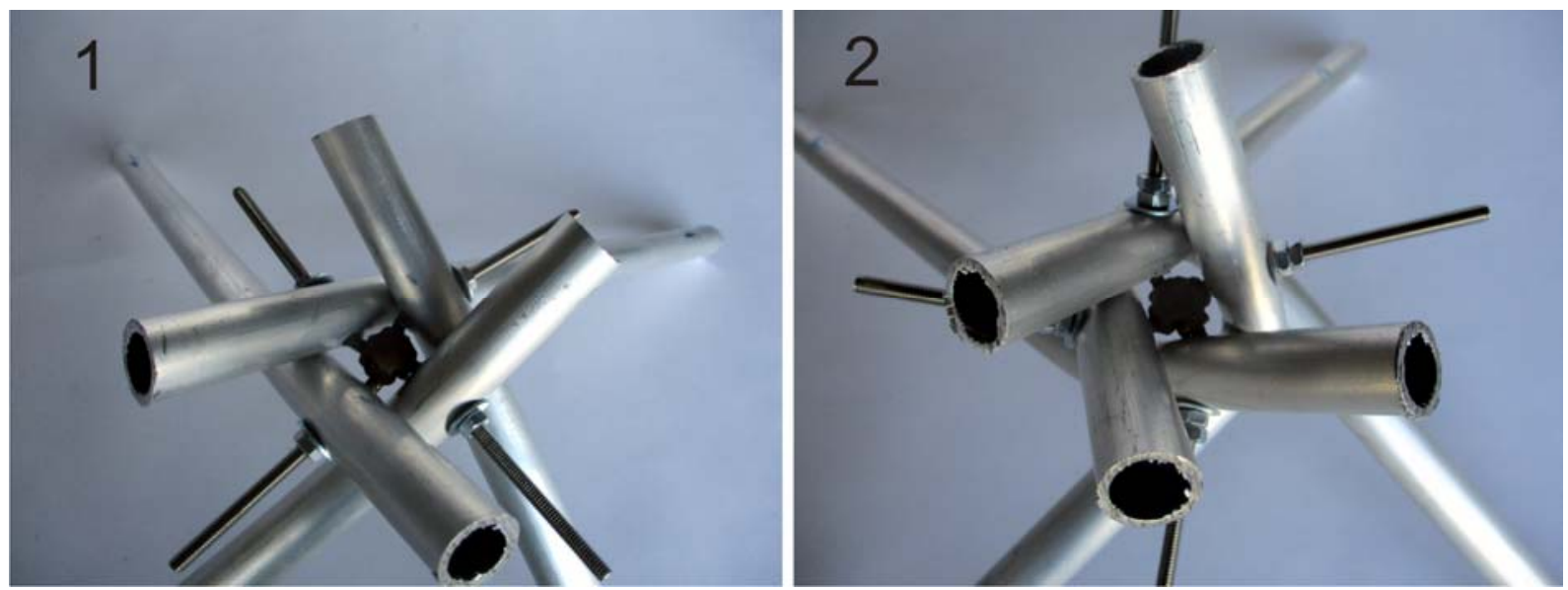

Figure 17.- Failure pattern for linkages constrained ends

\section{Conclusions.}

The studies and tests undertaken made it possible to demonstrate the efficacy of the designed linkage. In comparison with the articulated linkage, the reciprocal one notably improves the mechanical behaviour of the structure in terms of deformation limitation. Its behaviour restricts linkage turning to an extent equivalent to one degree of embedment, which in these tests amounts to $93.98 \%$, although it is higher in a real structure. Given that the dimensions of these types usually penalises deformation of the set more than the strength of the bars, the reciprocal linkage also makes it possible to use smaller cross-section lighter bars, with the resulting saving in material.

The tests that were performed would not be feasible with a conventional linkage. With free support it would be a mechanism, while with constrained support any imbalance would cause it to collapse. The reciprocal linkage design avoids these problems and makes it possible to construct strong stable 
linkages. Moreover, linkages of this type makes it possible to use, under acceptable conditions of service, structural designs that were unviable with articulated linkages, due to their high deformability and lack of rigidity, as is the case with flat meshes (figure 4).

The free support tests showed that the strength of the linkage is always greater than that of the bars under bending. A slight reduction of $1.91 \%$ only occurred in specimen 4 , and this was estimated to be acceptable. This is the normal situation in actual expandable structures, in which the bar ends are not constrained.

In the tests with constrained ends the aim was to analyse the resistance of the linkage in a way unrestricted by the bending of the bars. Although this situation is less usual in actual structures, it may be similar to what occurs in the supports. In this case the limit loads, in terms of elastic state as well as failure, are far greater. Collapse occurs due to the combined failure of the linkage pins and the bars due to reciprocal crushing.

The authors believe that the results obtained here demonstrate the structural efficacy of reciprocal linkages. In all cases failure occurred due to the limited strength of the structural bars rather than failure of the system. The use of reciprocal linkages makes it possible to construct expandable structures that are cheaper, simpler and better performing.

\section{Acknowledgements}

The authors would like to thank Guillermo Alonso and Silvia Miramontes of the Construction Laboratory of A Coruña EUAT for their help and collaboration in carrying out the tests.

\section{Funding}

This work was supported by the Ministry of the Economy and Competitiveness of the Kingdom of Spain [grant number BIA2016-79459-R]. This study is a part of the research project "Expandable and modular constructions for humanitarian disasters"

\section{References:}

[1] Pérez Piñero E, Estructura reticular estérea plegable. Spanish Patent 266801. 1961.

[2] Pérez Piñero E, Estructures reticulées. L'Architecture d'Aujourd'hui 1968;141: 76-81.

[3] Escrig Pallares F, Pérez-Valcárcel J, Estructuras espaciales desplegables curvas. Informes de la Construcción 1988; 39(393) : 53-71.

[4] Pérez-Valcárcel J, Escrig F, Martín E, Vázquez J.A, Analysis of expandable domes of squared modulus with self-folding roofing plates. In: proceedings of the IASS '95 international symposium 'Spatial Structures: Heritage, Present and Future', Milan, Italy; 1995. Vol 2: 551558.

[5] Escrig Pallares F, Sánchez Sánchez J. Estructura plegable de malla para la cubrición de recintos. Spanish Patent 2158787 A1. 1999.

[6] Hernández Merchán C. Deployable Structures. In: MARAS '91, international conference on mobile and rapidly assembled structures, computational mechanics publications, Southampton, 1991: 237-248.

[7] Gantes C, Connor JJ, Logcher RD. Combining Numerical Analysis and Engineering Judgement To Design Deployable Structures. Computers \& Structures 1991; 40(2): 431-440.

[8] Hoberman C. The art and science of folding structures. Sites 1992; 24: 34-53.

[9] Sánchez Cuenca L. Geometric models for expandable structures. In: MARAS ‘96, 2nd international conference on mobile and rapidly assembled structures, Computational Mechanics Publications, Seville; 1996: 93-102.

[10] De Temmerman N. Design and analysis of deployable bar structures for mobile architectural applications. [Ph. D. Thesis]. Brussels: Vrije Universiteit Brussels; 2007.

[11] Begiristain Mitxelena J. Sistemas estructurales desplegables para infraestructuras de intervención urbana autoconstruidas. [Ph. D. Thesis]. San Sebastián: Universidad del País Vasco; 2015.

[12] Arnouts LIW, Massarta TJ, De Temmerman N, Berke PZ. Computational modelling of the transformation of bistable scissor structures with geometrical imperfections. Engineering Structures 2018; 177: 409-20.

https://doi.org/10.1016/j.engstruct.2018.08.108 
[13] Pérez Belda E, Pérez Almagro $C$. The deployable architecture commemorates the 25 years of peace. 50 th Anniversary of Emilio Pérez Piñero's Pavilion. EGA 2016; 28: 146-55. doi: 10.4995/ega.20166307.

[14] Escrig F, Pérez-Valcárcel, J. Deployable Cover on a Swimming Pool in Seville. Bulletin of the International Association for Shell and Spatial Structures 1996; 37(120): 39-70.

[15] Sánchez J, Escrig F, Pérez-Valcárcel J. The adventure of covering a swimming-pool with an Xframe structure. In: MARAS ' 96 , 2nd international conference on mobile and rapidly assembled structures, Computational Mechanics Publications, Seville; 1996: 113-122.

[16] D. G. Emmerich "Noeuds d'Assemblage Universels" 1996. French Patent $n^{\circ}$ FR1469641A.

[17] Gantes CJ. Deployable structures: analysis and design. Boston: WIT Press; 2001.

[18] Yenal Akgün, Charis J. Gantes, Werner Sobek, Koray Korkmaza, Konstantinos Kalochairetis. A novel adaptive spatial scissor-hinge structural mechanism for convertible roofs. Engineering Structures 2011; 33: 1365-1376.

[19] Roovers, K.; De Temmerman, N., Deployable scissor grids consisting of translational units. International Journal of Solids Structures, Vol. 121, 2017: 45-61. DOI: 10.10 16/j.ijsolstr.20 17.05.015

[20] Gómez Jáuregui, Valentín; Otero González, César Antonio; Manchado del Val, Cristina; Iglesias Prieto, Andrés; Gálvez Tomida, Akemi; Quilligan, Michael; Casey, Tom. 2015. Nudo de conexión para estructuras desplegables. Spanish Patent ES2555635B2.

[21] Arnouts, Liesbeth; Massart, J.; De Temmerman, Niels; Berke, Péter 2018. "Computational modelling of the transformation of bistable scissor structures with geometrical imperfections". Engineering Structures. Volume 177: 409-420. DOI: 10.1016/j.engstruct.2018.08.108.

[22] Sang-Hoon Lee D.; Popovic Larsen O. Seung-Deog Kim 2014. Design of Deployable Structure for Dome Type Emergency Shelter. Proceedings of the IASS-SLTE 2014 Symposium "Shells, Membranes and Spatial Structures: Footprints" 2014, Brasilia, Brazil

[23] P. Valcárcel, J.; Escrig, F.; Vázquez, J.A.; Domínguez, E. Recent Advances in Virtual Design of Expandable Structures. "Mobile and rapidly assembled Structures (MARAS'00)". Madrid. 2000: 45-54.

[24] Y. Yokosuka, T. Matsuzawa. Shape-finding Analysis for Variable Geometry Structures Formed by a Multilink Spatial Joint. New Proposals for Transformable Arquitecture, Engineering and Design. In the Honor of Emilio Pérez Piñero. Sevilla. 2013.

[25] Pérez-Valcárcel J, Escrig F, Domínguez E, Lamas V. Expandable Structures with Self-folding Stiffeners. In: Proceedings of IASS 1999 symposium 'From recent past to the next millennium', Madrid, Spain, 1999; Vol 2: D21- D30.

[26] Pérez-Valcárcel J, Muñoz-Vidal M, López-César I, Suárez Riestra F. Nudo autobloqueable para estructuras desplegables. Spanish Patent ES2653648. 2018. http://www.oepm.es/pdf/ES/0000/000/02/65/36/ES-2653648_B2.pdf

[27] Popovič Larsen O. Reciprocal frame architecture. Oxford: Elsevier. 2008.

[28] Popovič O, Sang-Hoon D. Reciprocal Frames (RFs) Used for Quick-built Deployable Emergency Shelters. In: Proceedings of IASS 2013 Symposium, Wroclaw, Poland, 2013., Publisher: IASS, Conference: Wroclaw, Poland, 23/09/13 - 23/09/13: 1-7

[29] Muñoz-Vidal M, López-César I, Pérez Valcárcel J, Suárez Riestra F. Deployable structures of multiple crossed arches. In: ICSA2019, 4th international conference on structures and architecture, Lisbon; 2019.

[30] Pérez-Valcárcel J, Muñoz-Vidal M, Suárez Riestra F. Freire Tellado MJ, López-César I, MuñizGómez S S et al. Estructura desplegable, edificación y método de construcción de una edificación. Spanish Patent P201831054. 2018. 